(C) Dr W. Junk Publishers, Dordrecht - Printed in the Netherlands.

\title{
Phylogenetic implications of karyotypic variation in the Batagurinae (Testudines: Emydidae)
}

\author{
J. L. Carr* \& J. W. Bickham \\ Department of Wildlife and Fisheries Sciences, Texas A\&M University, College Station, TX 77843, USA \\ *Present address: Department of Zoology, Southern Illinois University, Carbondale, IL 62901, USA
}

\begin{abstract}
The present study examined karyotypes of 16 genera and, along with previous reports, chromosomal data are now available for 18 of the 23 recognized batagurine genera. There are no karyotypic data available for the members of McDowell's (1964) Hardella complex. The Batagur, Heosemys and Geoemyda complexes retain the hypothesized primitive karyotype for the subfamily $(2 n=52)$. All the genera in these three complexes have been examined except Batagur and Annamemys. The Orlitia complex is karyotypically distinct with $2 n=50$ and the NOR located terminally on a large microchromosome. The genus Malayemys inclusion in the Batagur complex is not supported. Malayemys is characterized by a $2 n=50$ karyotype, with the NOR located interstitially on a large microchromosome. The Malayemys complex is erected to contain this genus at a point intermediate between the Orlitia complex and the subfamily Emydinae. Malayemys and the emydines are karyotypically indistinguishable. The Neotropical genus Rhinoclemmys (Geoemyda complex) differs only slightly from the primitive batagurine karyotype in the position of the NOR. The species $R$. funerea and $R$. punctularia further differ in possessing one less metacentric macrochomosome. An interesting situation involves two subspecies of $R$. punctularia. The nominate subspecies is characterized by a $2 \mathrm{n}=56$ karyotype, while $R$. p. melanosterna reportedly has a $2 n=52$ karyotype. Such a difference is interpreted as indicative of genetic differentiation between the two forms of a magnitude inconsistent with considering them as conspecific. Taken together with zoogeographic considerations, the karyotypic difference between the forms $R$. p. punctularia and $R$. p. melanosterna seem sufficient to warrant species distinction for $R$. melanosterna as previously suggested by Pritchard (1979b).
\end{abstract}

\section{Introduction}

Emydids constitute the largest family of turtles, containing nearly 40 percent of extant species. This large and diverse group of the most common and conspicuous turtles inhabiting the northern hemisphere remained largely unstudied on a global scale until recently. Not until 1964 were some relationships proposed which have been widely accepted. McDowell (1964) partitioned the group (which he considered a subfamily of the Testudinidae) into a primarily New World Emydinae and a primarily Old World Batagurinae. In addition, he allotted the genera in each subfamily into related groups, termed generic complexes. Bramble's (1974) study has been the only serious attempt to address generic relationships within the Batagurinae since McDowell (1964).

A rather liberal acceptance of genera characterizes the classification of batagurines recognized here (Table 1). Morphological studies have, in several cases, reached discordant conclusions regarding generic distinctions and phylogenetic relationships within the Batagurinae (Loveridge \& Williams, 1957; Smith \& James, 1958; McDowell, 1961, 1964; Parsons, 1968; Bramble, 1974; Albrecht, 1976). Recent listings of turtle species also differ in the generic designations of batagurines (Wermuth 
Table I. The genera of batagurines, after McDowell (1964), Bramble (1974), Wermuth and Mertens (1977), and Pritchard (1979a).

\begin{tabular}{cc}
\hline Batagur complex & Geoemyda complex \\
Batagur & Annamemys \\
Callagur & Geoemyda \\
Chinemys & Mauremys \\
Hieremys & Melanochelys \\
Kachuga & Notochelys \\
Malayemys & Rhinoclemmys \\
Ocadia & Sacalia \\
Hardella complex & Heosemys complex \\
Geoclemmys & Cuora \\
Hardella & Cyclemys \\
Morenia & Heosemys \\
& Pyxidea \\
Orlitia complex & \\
Orlitia & \\
Siebenrockiella & \\
\hline
\end{tabular}

\& Mertens, 1977; Pritchard, 1979a).

Previous studies have noted a degree of variability in diploid number in emydids not found among other cryptodiran families (Stock, 1972; Bickham, 1975; Bickham \& Baker, 1976a, 1979; Bickham \& Carr, 1983; Killebrew, 1977). The Emydinae is karyotypically homogeneous (Bickham \& Carr, 1983), but the Batagurinae is variable. A diploid number of 52 appears characteristic of most batagurines (Table 2), but there are several reports of $2 \mathrm{n}=50$ in some species and two reports of $2 \mathrm{n}=56$ in Rhinoclemmys punctularia. An exploration and explication of this variability in a phylogenetic context is the subject of this account.

\section{Material and methods}

Standard karyotypes were routinely prepared

Table 2. Summary of the karyotypic data considered in the present study.

\begin{tabular}{|c|c|c|c|c|c|c|c|}
\hline \multirow[t]{2}{*}{ Taxon } & \multirow[t]{2}{*}{$2 n$} & \multirow[t]{2}{*}{$\mathrm{A}: \mathrm{B}: \mathrm{C}$} & \multirow{2}{*}{$\frac{\text { Numbers of Specimens Examined }}{\text { male:female:juvenile }}$} & \multicolumn{4}{|c|}{ Figure } \\
\hline & & & & Std. & G-band & C-band & NOR \\
\hline Callagur borneoensis & 52 & $9: 5: 12$ & $0: 0: 1$ & NS & $2 \mathrm{c}$ & NS & NS \\
\hline Chinemys kwangtungensis & 52 & $9: 5: 12$ & $0: 0: 1$ & $2 a$ & - & $1 \mathrm{c}$ & - \\
\hline C. reevesii & 52 & $9: 5: 12$ & $0: 0: 1$ & - & + & - & - \\
\hline Cuora ambionensis & 52 & $9: 5: 12$ & $0: 1$ & $8 a$ & $8 b$ & NS & NS \\
\hline C. trifasciata & 52 & $9: 5: 12$ & $1: 0$ & $8 \mathrm{c}$ & - & - & - \\
\hline Cyclemys dentata & 52 & $9: 5: 12$ & $0: 0: 1$ & - & - & + & - \\
\hline Heosemys grandis & 52 & $9: 5: 12$ & $0: 1$ & $7 \mathrm{c}$ & - & - & - \\
\hline H. spinosa & 52 & $9: 5: 12$ & $0: 1$ & NS & - & - & NS \\
\hline Hieremys annandalii & 52 & $9: 5: 12$ & $0: 0: 1$ & NS & $2 b$ & NS & NS \\
\hline Malayemys subtrijuga & 50 & $8: 5: 12$ & $0: 0: 1$ & NS & $9 b$ & - & $10 \mathrm{c}$ \\
\hline Mauremys japonica & 52 & $9: 5: 12$ & $1: 0$ & $3 a$ & - & - & - \\
\hline Melanochelys trijuga & 52 & $9: 5: 12$ & $1: 1$ & $3 b$ & - & - & - \\
\hline Notochelys platynota & 52 & $9: 5: 12$ & $0: 0: 1$ & $3 c$ & - & - & - \\
\hline Ocadia sinensis & 52 & $9: 5: 12$ & $0: 2$ & $1 \mathrm{a}$ & $1 b$ & NS & $1 \mathrm{~d}$ \\
\hline Orlitia borneensis & 50 & $8: 5: 12$ & $0: 1$ & NS & $9 a$ & NS & $10 \mathrm{~b}$ \\
\hline Pyxidea mouhotii & 52 & $9: 5: 12$ & $0: 1$ & $7 \mathrm{~b}$ & - & - & NS \\
\hline Rhinoclemmys areolata & 52 & $9: 5: 12$ & $0: 1$ & $4 c$ & NS & $6 c$ & $6 a$ \\
\hline R. funerea & 52 & $8: 5: 13$ & $1: 0$ & $5 a$ & NS & NS & NS \\
\hline R. pulcherrima incisa & 52 & $9: 5: 12$ & $2: 0$ & $4 b$ & $7 a$ & - & NS \\
\hline R. p. manni & 52 & $9: 5: 12$ & $3: 4$ & $4 a$ & NS & NS & $6 \mathrm{~b}$ \\
\hline R. punctularia punctularia & 56 & $8: 5: 15$ & $2: 1$ & $5 b$ & $x$ & $x$ & - \\
\hline R. rubida & 52 & $9: 5: 12$ & $0: 1: 1$ & $5 c$ & - & - & - \\
\hline Sacalia bealei & 52 & $9: 5: 12$ & $1: 0$ & y & $\mathrm{x}$ & $\mathrm{x}$ & - \\
\hline Siebenrockiella crassicollis & 50 & $8: 5: 12$ & $6: 4$ & $*$ & $*$ & $*$ & $10 \mathrm{a}$ \\
\hline
\end{tabular}

* See figures in Carr and Bickham (1981).

+ See figures in Haiduk and Bickham (1982).

$x$ See figures in Bickham and Baker (1976a).

y See figures in Bickham (1975).

NS Not shown. 
directly from spleen according to the procedure of Bickham (1975), with modifications as noted in Carr and Bickham (1981). Cells utilized for differential staining techniques were obtained from heart fibroblast cell cultures as described in Sites et al. (1979). The modifications of Seabright's (1971) and Sumner's (1972) techniques as described by Sites et al. (1979) were used for G-banding and C-banding, respectively. The Ag-AS technique of Goodpasture and Bloom (1975) was employed for staining nucleolus organizer regions (NOR).

The following specimens examined are deposited in the Texas Cooperative Wildlife Collection of Texas A\&M University: Callagur borneoensis, TCWC 58357; Chinemys kwangtungensis, TCWC 60716; Chinemys reevesii, TCWC 56736; Cuora amboinensis, TCWC 56951; Cuora trifasciata, TCWC 58349; Cyclemys dentata, TCWC 56965; Heosemys grandis, TCWC 58350; Heosemys spinosa, TCWC 56953; Hieremys annandalii, TCWC 56935, 56959; Malayemys subtrijuga, TCWC 58364; Mauremys japonica, TCWC 60719; Notochelys platynota, TCWC 58366; Ocadia sinensis, TCWC 56955, 57879; Pyxidea mouhotii, TCWC 58358; Rhinoclemmys areolata, TCWC 57878; $R$. funerea, TCWC 58337; $R$. rubida, TCWC 58355; $R$. punctularia punctularia, TCWC 58616-17, 58627; $R$. pulcherrima incisa, TCWC 55016, 58375; $R . p$. manni, TCWC 56862-63, 56911-14, 56999; Sacalia bealei, TCWC 60718; Siebenrockiella crassicollis, TCWC 56942-43, 58204, 58344-47, 58360, 58648. Specimens examined which are deposited in other collections include: Melanochelys trijuga, University of Utah 17502; Orlitia borneensis, E. O. Moll, private collection; Rhinoclemmys rubida, Los Angeles County Museum 131362; Siebenrockiella crassicollis, LACM 116540.

The terminology for centromere position used herein is that of Bickham (1975) as adapted from Levan et al. (1964). The karyotype is divided into three groups based on relative size and centromere position. Group A chromosomes are characterized as either metacentric or submetacentric macrochromosomes. Group B macrochromosomes are either subtelocentric or telocentric. The microchromosomes of Group $\mathrm{C}$ are all so small that it is difficult to consistently determine centromere position, or even homologs in G-band preparations, with any certainty.

\section{Results}

A summary of the karyotypic data for each species is presented in Table 2, as are references to the illustrations (Figs. 1-10). In general, groups of genera were found to be karyotypically homogeneous and therefore the acçounts which follow are organized by generic complex. The arrangement of chromosome pairs in each of the aforementioned three groups is presented in the form $A: B: C$.

\section{Batagur complex}

The genera Callagur, Chinemys, Hieremys, Malayemys, and Ocadia were included in the present study. Several species of Kachuga have previously been studied by other workers and some reference to that work will be made. Batagur is the only genus in this complex which has not been studied.

The species Callagur borneoensis, Chinemys $k$ wangtungensis, $C$. reevesii, Hieremys annandalii, and Ocadia sinensis all possess indistinguishable $2 \mathrm{n}=52$ (9:5:12) standard karyotypes (Figs. 1a, 2a). G-banded karyotypes were obtained from Hieremys (Fig. 2b), Ocadia (Fig. 1b), and $C$. reevesii (Bickham et al., 1980) and are indistinguishable as well. It is the same G-band pattern as that illustrated by Bickham and Baker (1976a) for Sacalia bealei. C-bands of Ocadia and C. kwangtungensis (Fig. 1c) show the ninth group A macrochromosome pair to be largely heterochromatic, as is also the case in Sacalia (Bickham \& Baker, 1976a). Silver staining shows the single pair of NORs to be located telomerically on the smallest group A macrochromosome pair in Callagur and Ocadia (Fig. 1d).

Unlike the other members of the Batagur complex, Malayemys has a diploid number of 50 (8:5:12), with one less pair of group A macrochromosomes. The G-banding pattern of this species (Fig. 9b) is the same as the emydine genera Graptemys, Pseudemys, and Terrapene (Bickham \& Baker, 1979), which is identical to the macrochromosomes of the batagurines mentioned above (excepting pair 9A). The NOR of Malayemys appears on one of the largest microchromosome pairs proximal to the centromere (Fig. 10c). Based upon gross morphology, G-band, and NOR location, no karyotypic distinction between Malayemys and emydines (Bickham \& Baker, 1976a, 1979 and unpublished) can be made. 


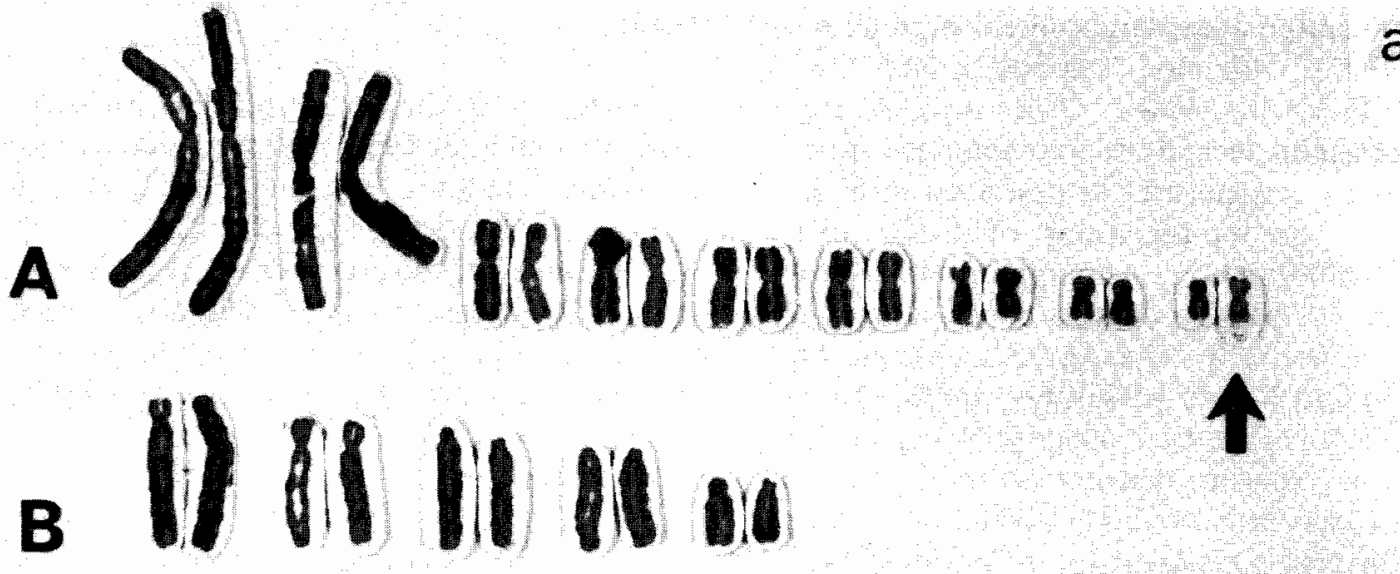

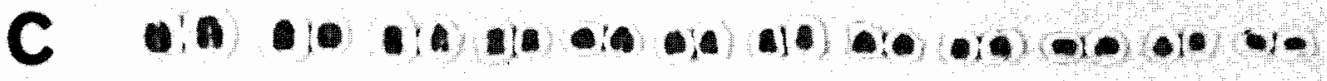

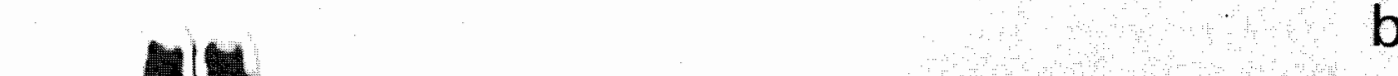

b

A

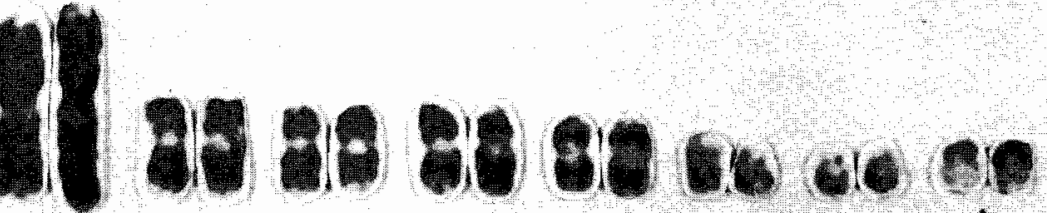

B 9000
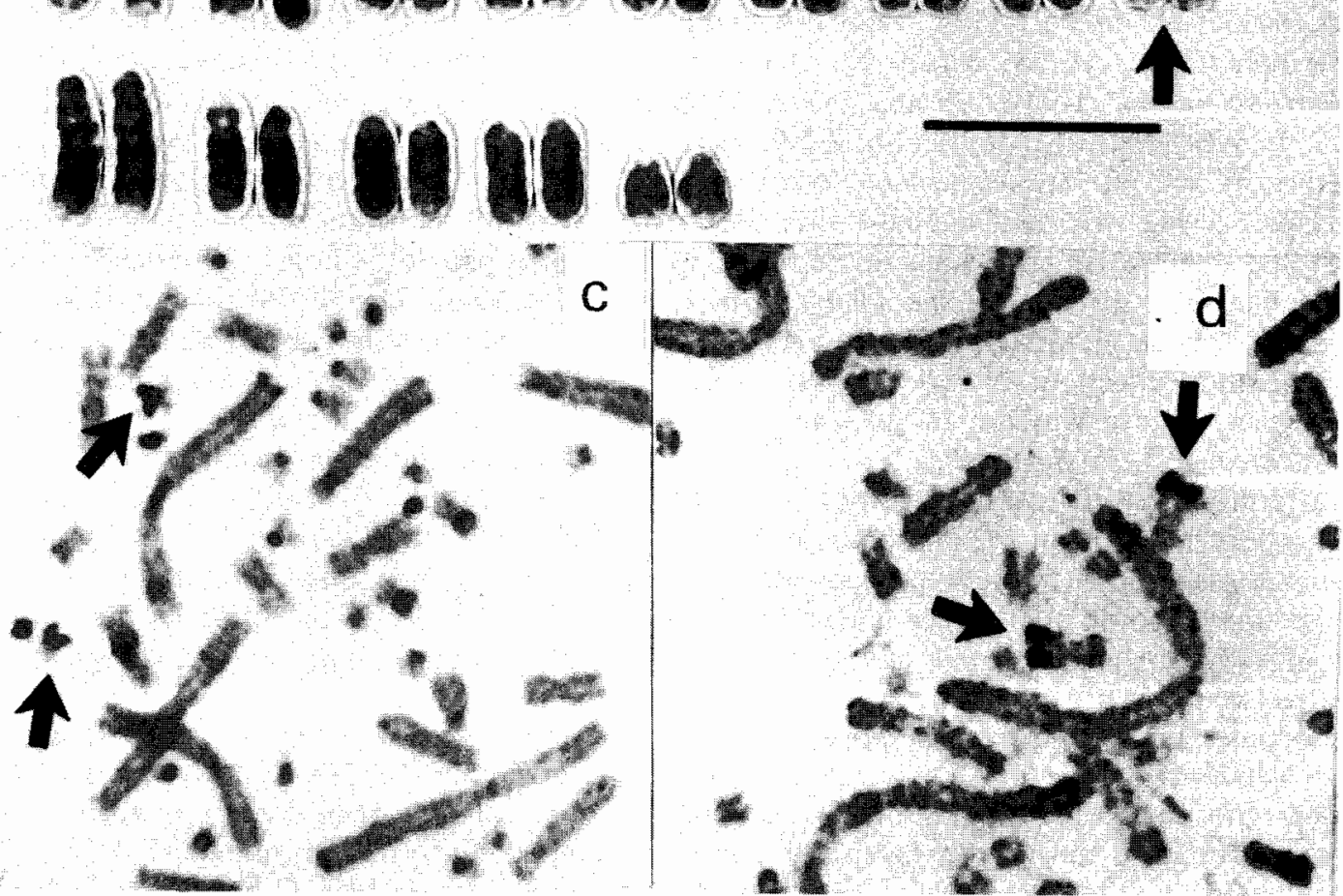

Fig. 1. (a) Standard karyotype of Ocadia sinensis. Arrows in this and all subsequent figures identify the NOR-bearing chromosome, if identifiable. Chromosomes are arranged into groups A:B:C as described in the text. (b) G-band karyotype of $O$. sinensis. Bar, in this and subsequent figures, is 10 microns. (c) C-banded partial metaphase of Chinemys kwangtungensis. (d) Silver stained partial metaphase of $O$. sinensis. 
93

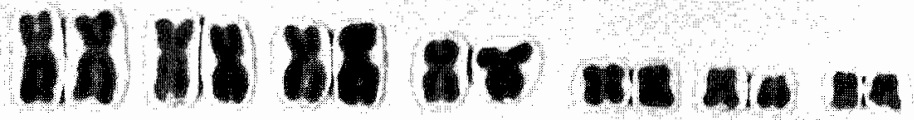
II II IS 010

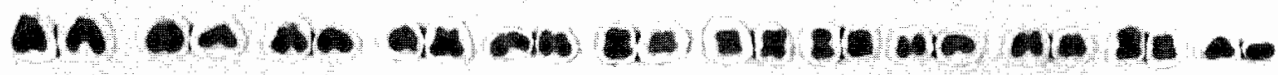

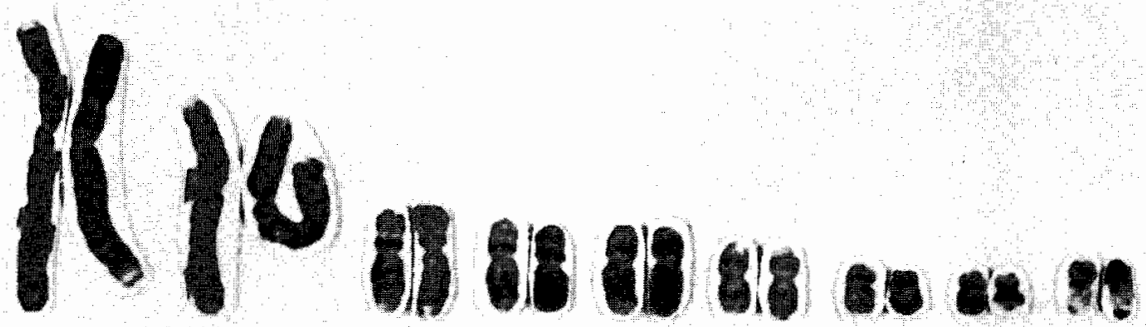

b

1101010

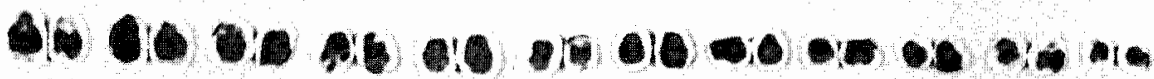

1) 38888838 .4.

C

8880 ob

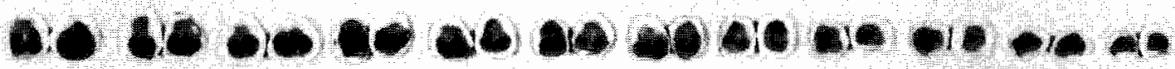

Fig. 2. (a) Standard karyotype of Chinemys kwangtungensis. (b) G-band karyotype of Hieremys annandalii. (c) G-band karyotype of Callagur borneoensis. 

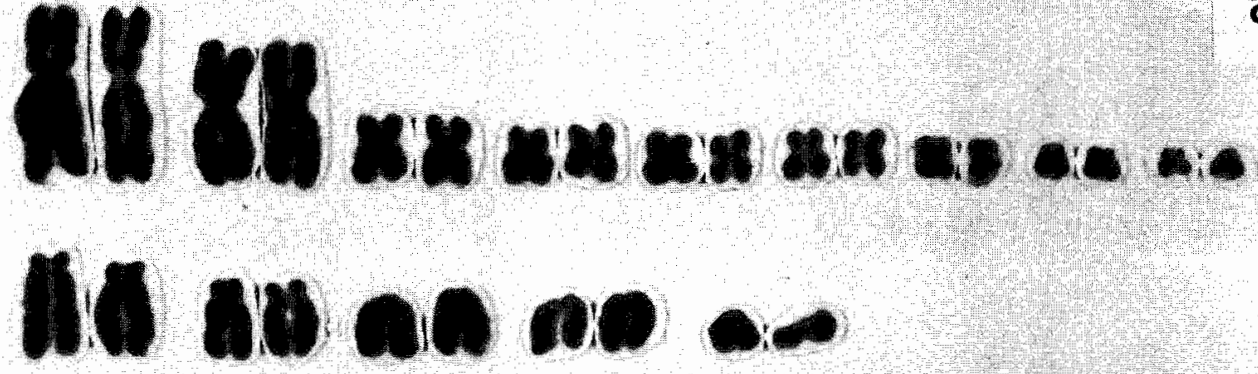

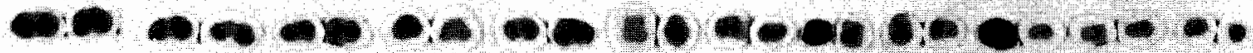

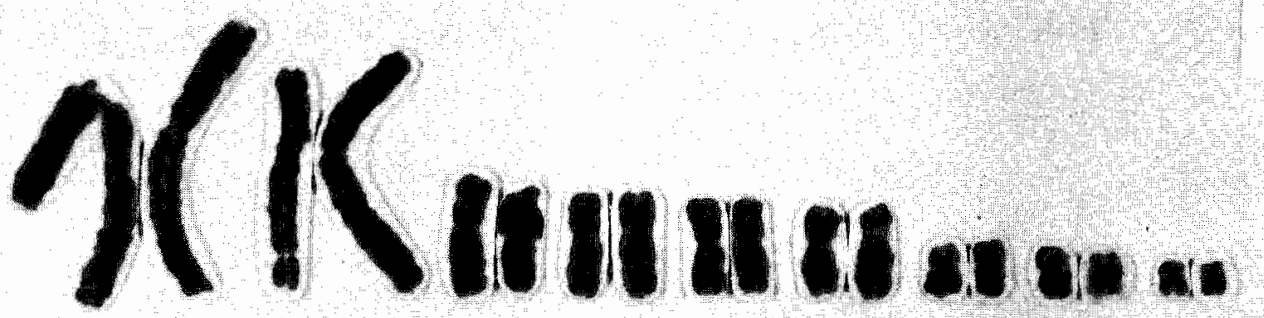

b

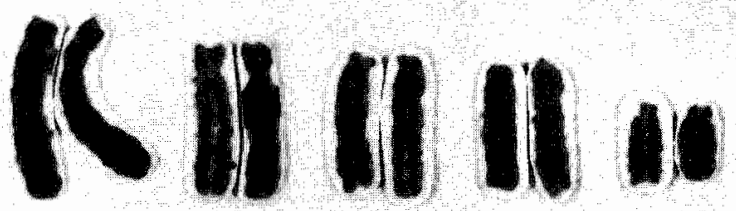

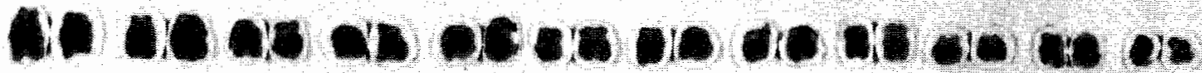

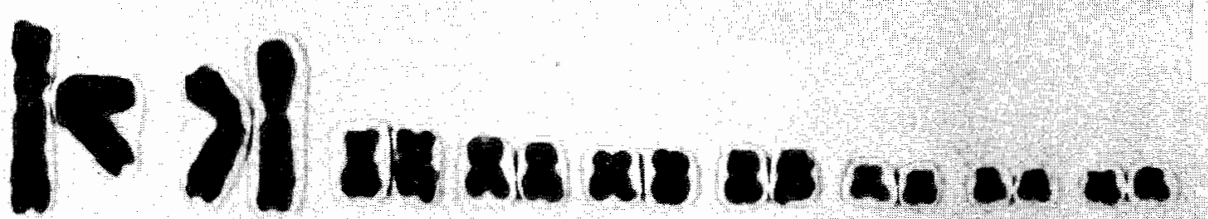

If 10 on of an

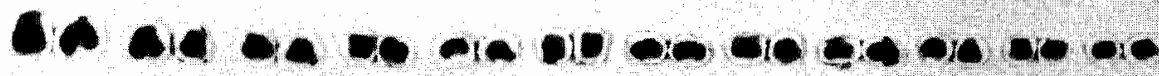

Fig. 3. Standard karyotypes of (a) Mauremys japonica, (b) Melanochelys trijuga, (c) Notochelys platynota. 


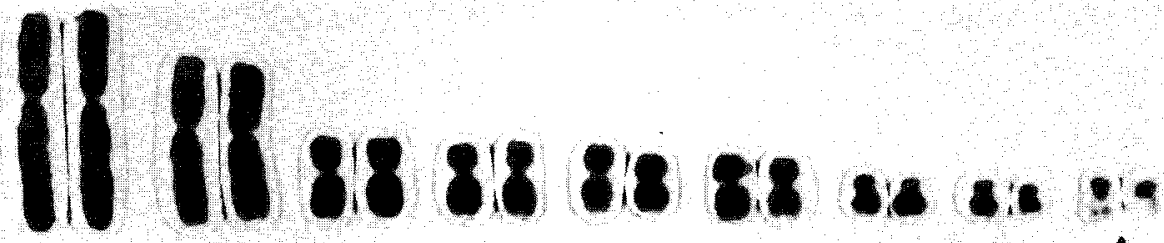

a Ii 10000000

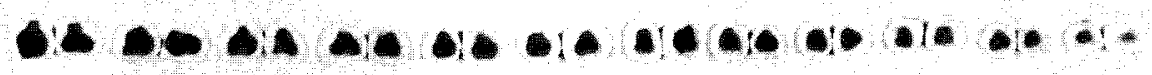

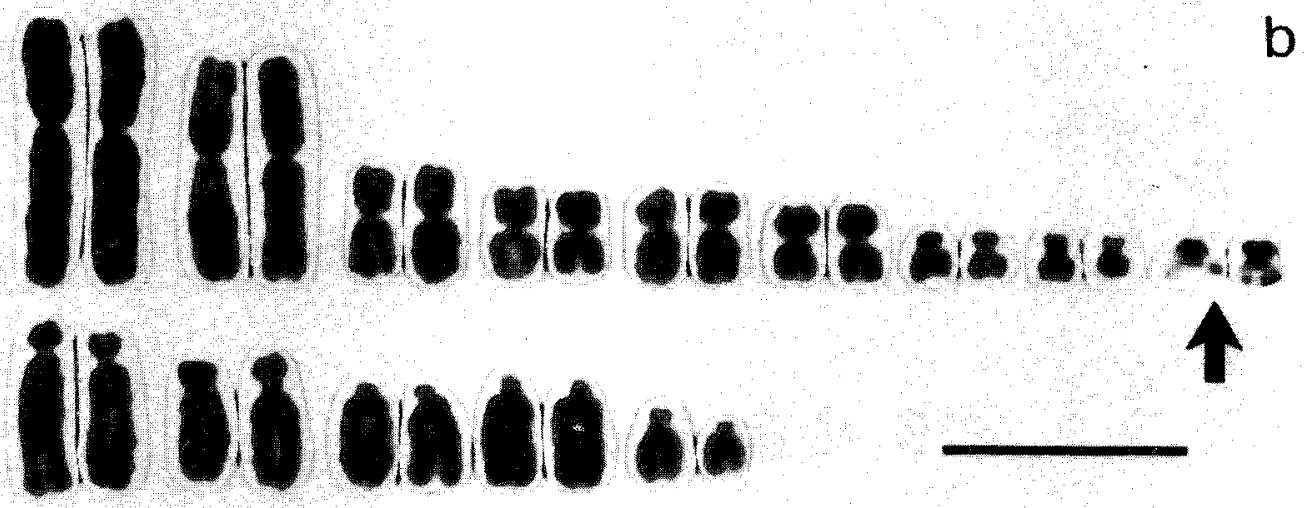

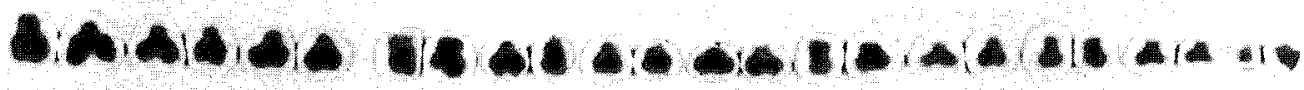

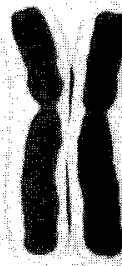

C

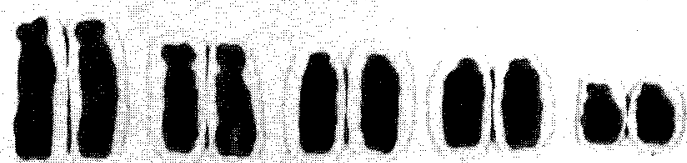

A

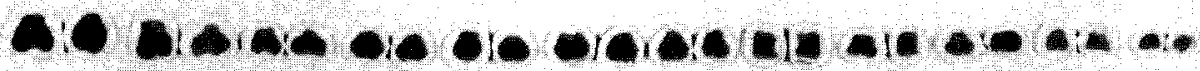

Fig. 4. Standard karyotypes of (a) Rhinoclemmys pulcherrima manni, (b) R. p. incisa, (c) R. areolata. 

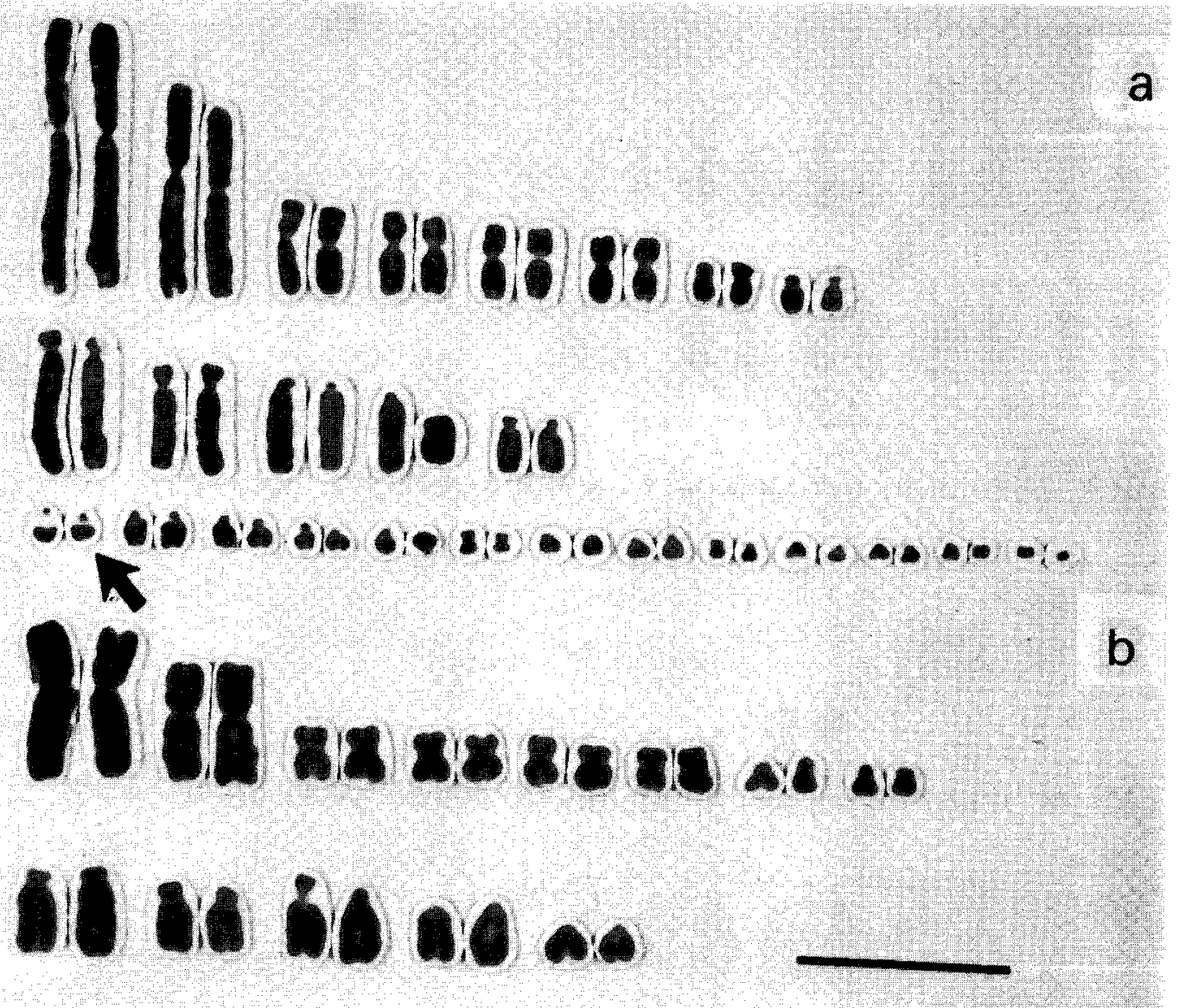

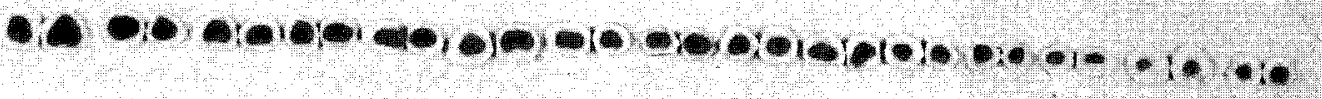

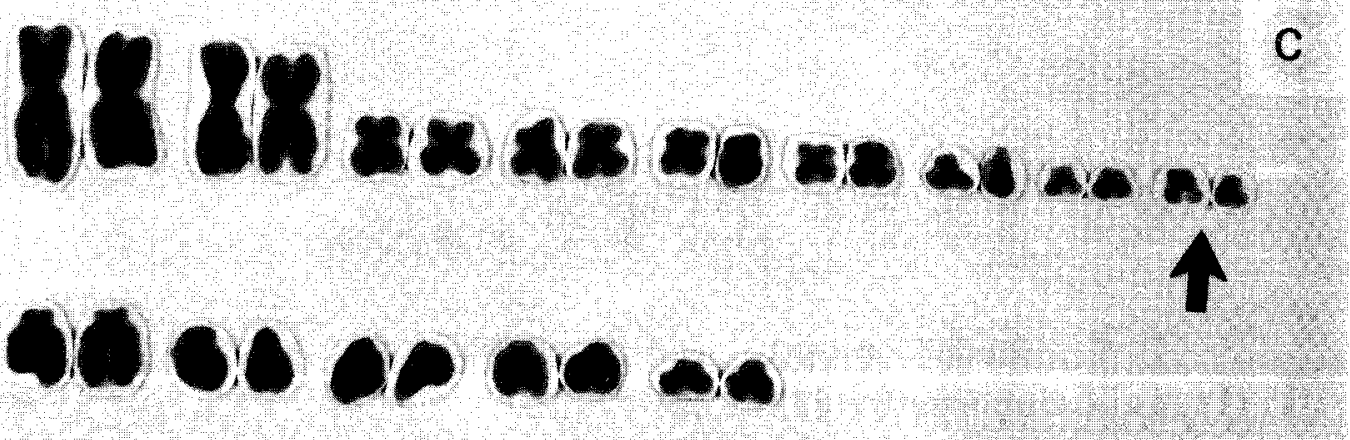

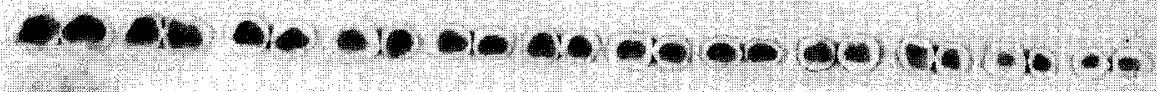

Fig. 5. Standard karyotypes of (a) Rhinoclemmys funerea, (b) R. punctularia punctularia, (c) R. rubida. 


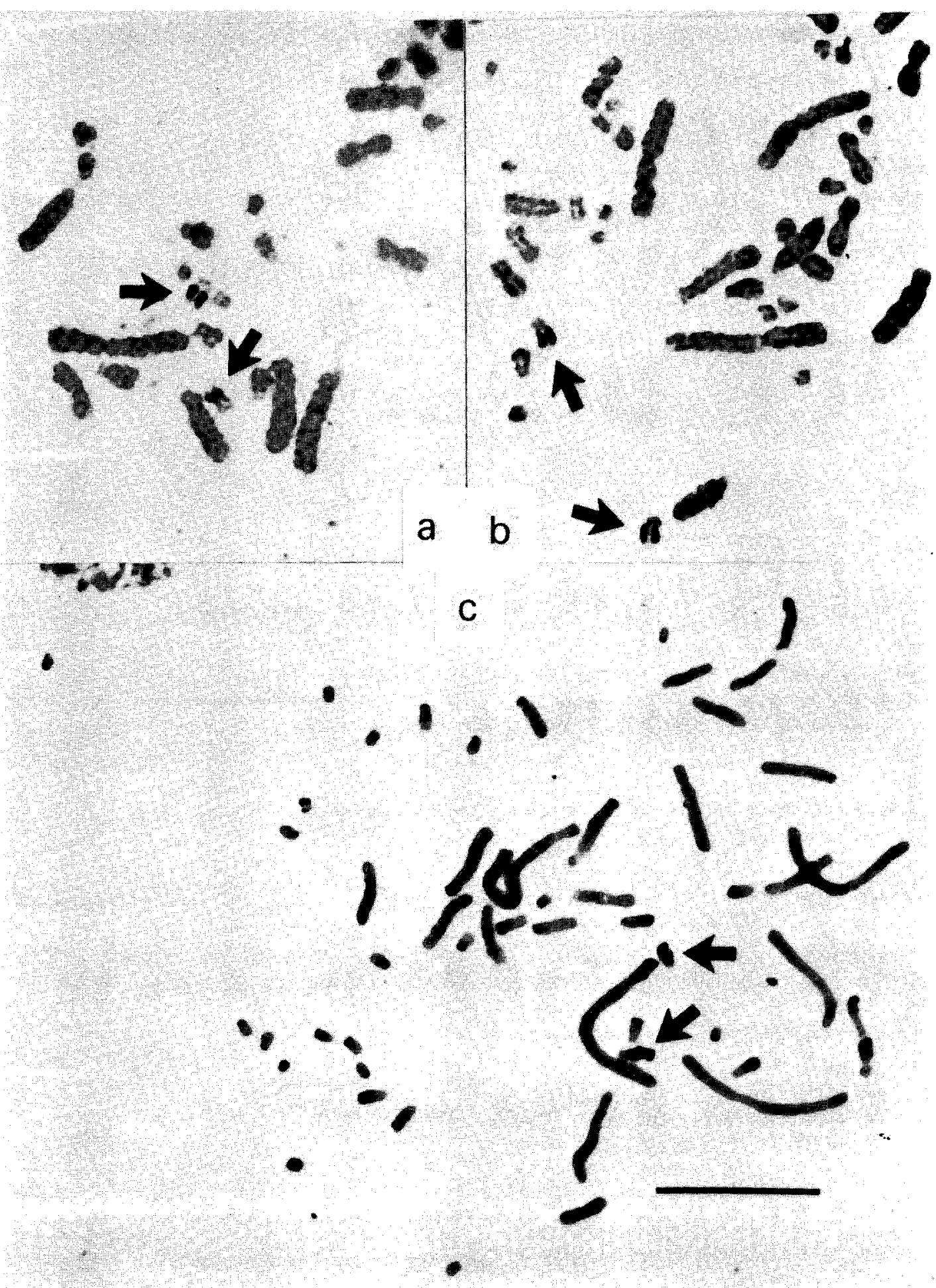

Fig. 6. Silver stained partial metaphase plates of (a) Rhinoclemmys areolata and (b) $R$. pulcherrima manni. (c) C-banded partial metaphase plate of $R$. areolata. 


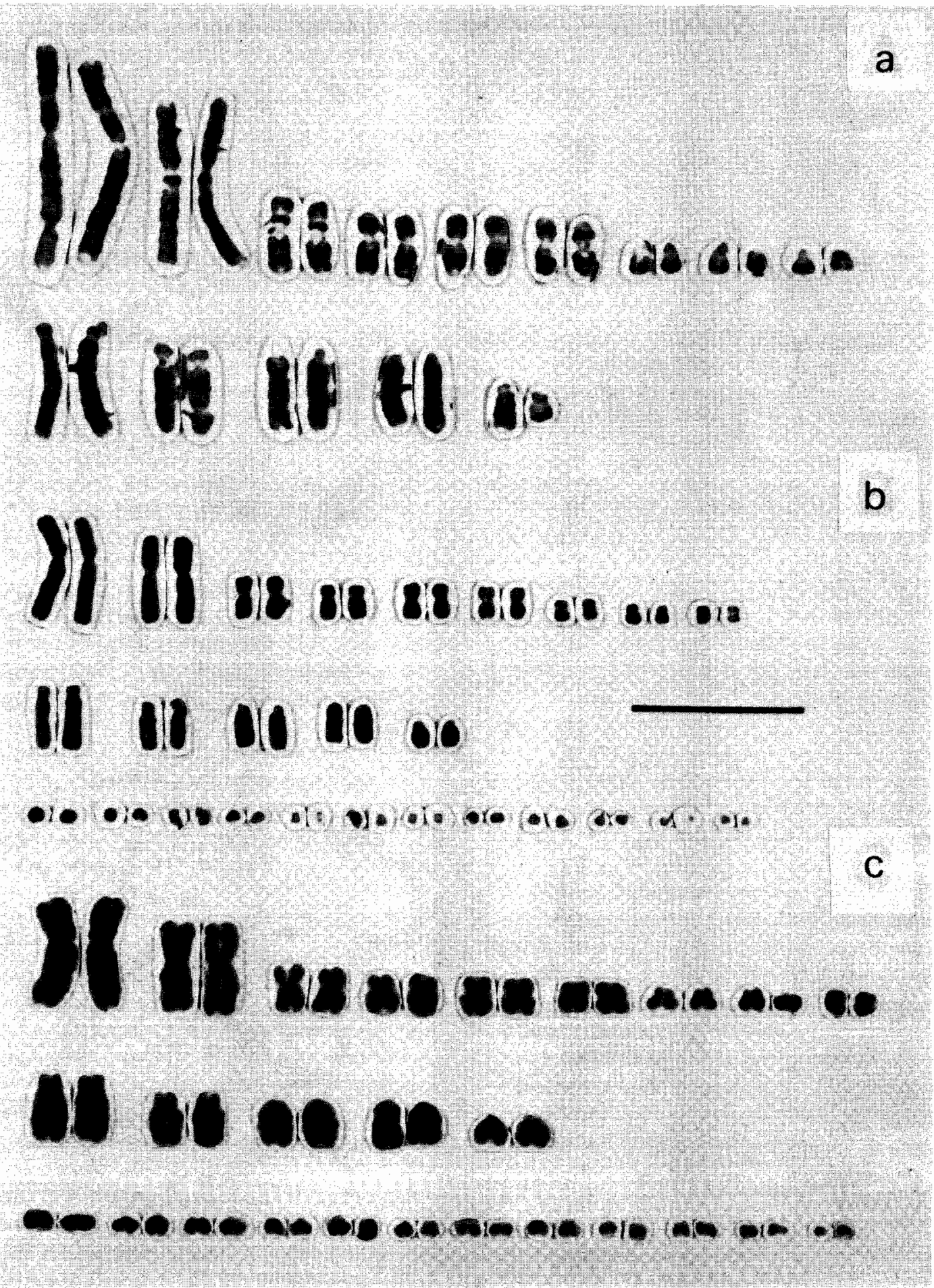

Fig. 7. (a) G-banded macrochromosomes of Rhinoclemmys pulcherrima incisa. Standard karyotypes of (b) Pyxidea mohoutii and (c) Heosemys grandis. 


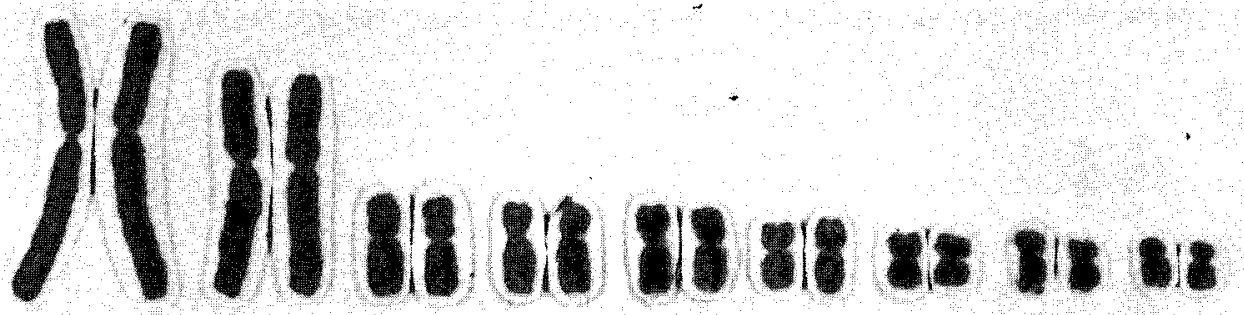

a

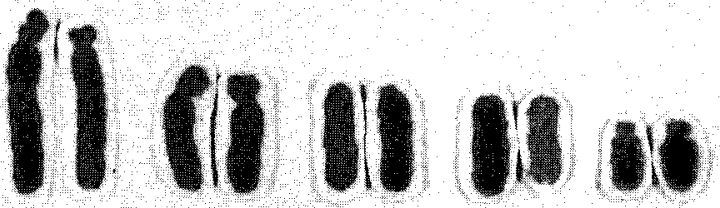

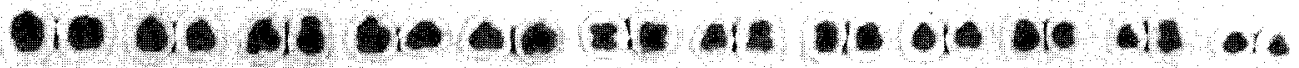
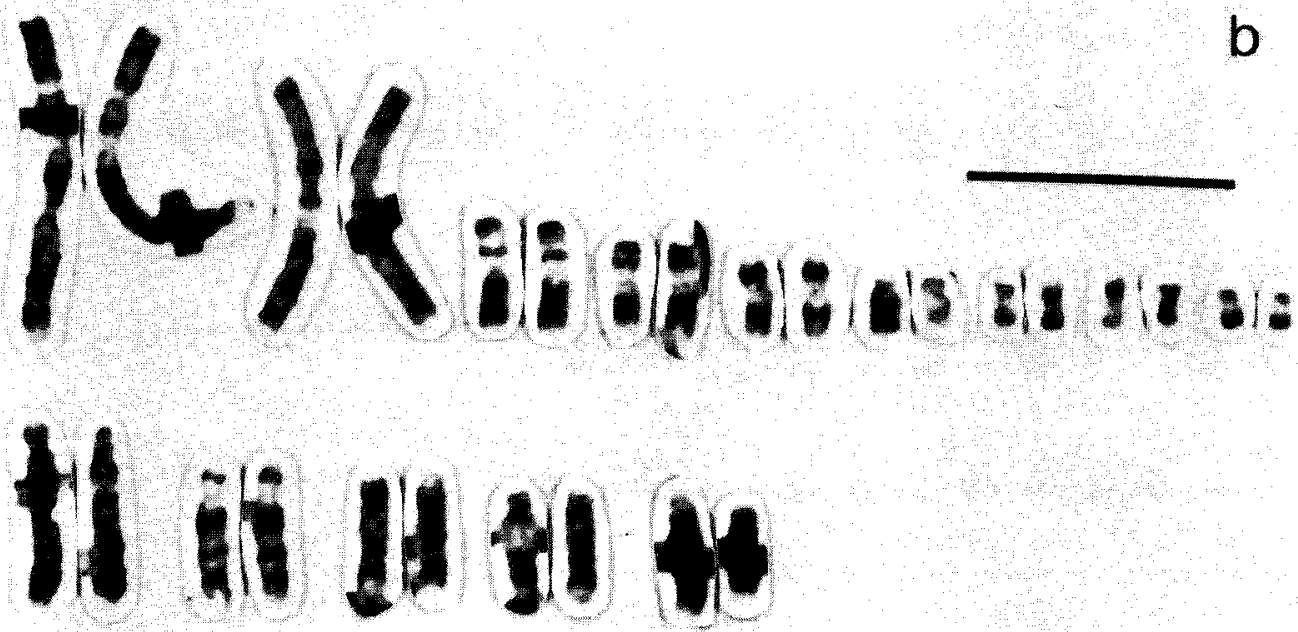

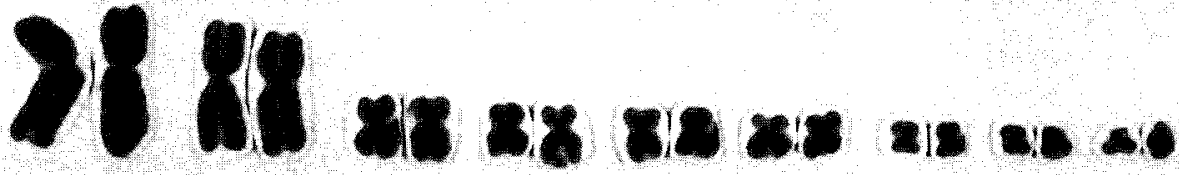

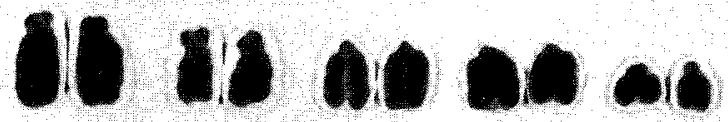

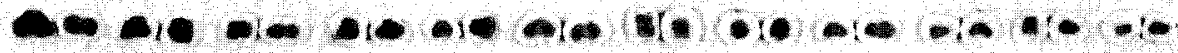

Fig. 8. Standard karyotype (a) and G-band karyotype (b) of Cuora amboinensis. (c) Standard karyotype of C. trifasciata. 


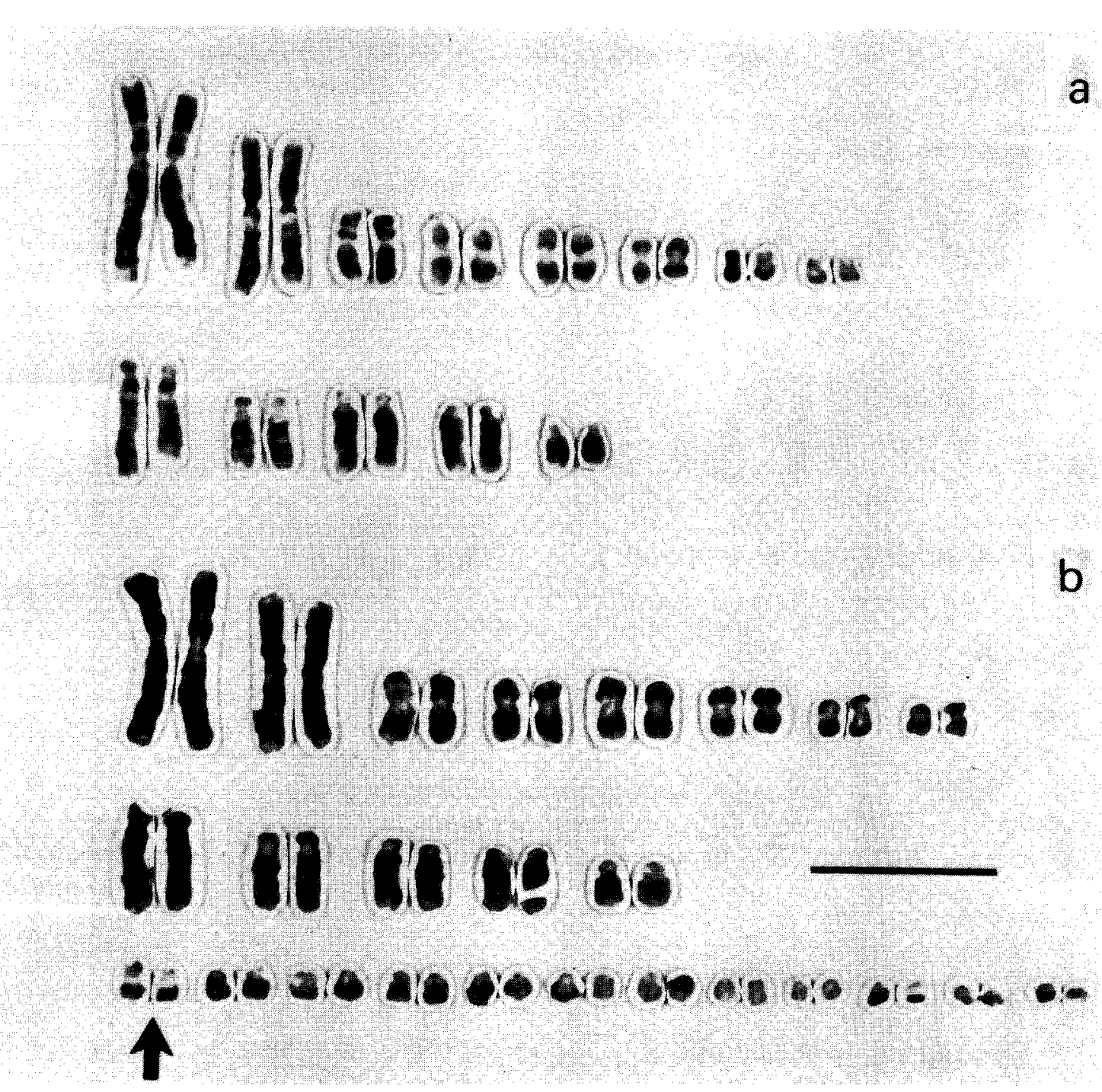

Fig. 9. (a) G-banded macrochromosomes of Orlitia borneensis. (b) G-bana' karyotype of Malayemys subtrijuga.

\section{Geoemyda complex}

The present study includes karyotypic data on Melanochelys, Mauremys, Notochelys, and Rhinoclemmys. Comparative data are available in the literature for the genera Geoemyda and Sacalia (see references in Bickham \& Carr, 1983). Annamemys has not been examined.

Mauremys (Fig. 3a), Melanochelys trijuja (Fig. 3b), Notochelys (Fig. 3c), and most Rhinoclemmys (Figs. 4 and 5) have the same gross morphology that characterizes most of the Batagur complex, namely $2 n=52(9: 5: 12)$. Reference to the literature reveals that the genera Geoemyda and Sacalia possess this same karyotype. The data available at present do not indicate a distinction in the number of macrochromosomes between some members of the genus Rhinoclemmys and the Old World batagurines with $2 \mathrm{n}=52$ as was interpreted by Bickham and Baker (1976a). The taxa $R$. p. incisa, $R$. p. manni, $R$. areolata, and $R$. rubida possess karyotypes with $2 \mathrm{n}=52$, (9:5:12) (Figs. 4 and 5). However, the smallest group A pair (9A) possesses a distinct, interstitial, secondary constriction that 


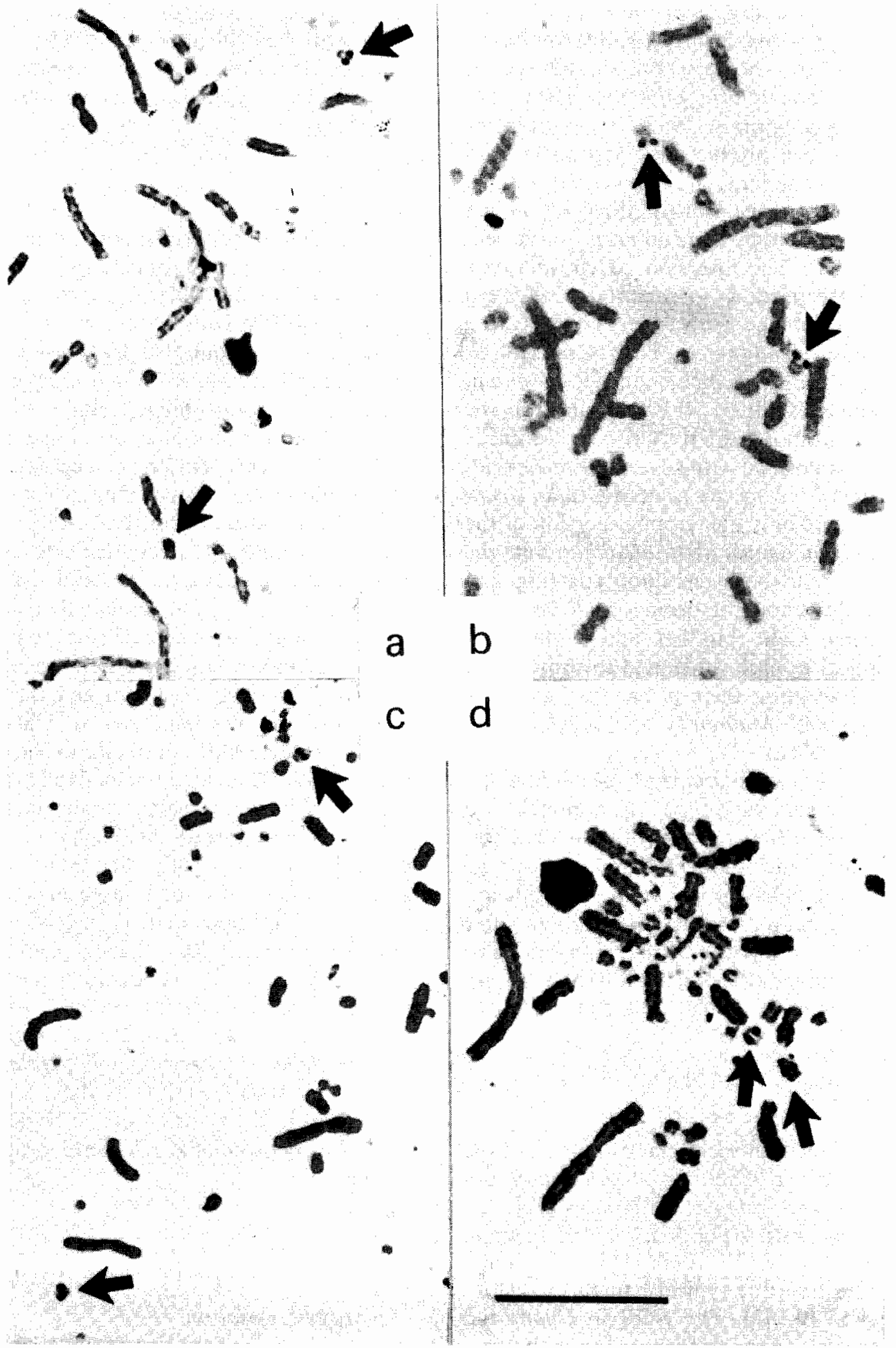

Fig. 10. Silver stained partial metaphases of (a) Siebenrockiella crassicollis, (b) Orlitia borneensis, (c) Malayemys subtrijuga, and (d) Clemmys guttata, Emydinae. 
differentiates the karyotypes of these species from the presumed primitive $2 n=52$ (9:5:12) karyotype (e.g., Fig. 1a). There is no detectable secondary constriction in $R$. punctularia punctularia (Fig. Sb) and only 8 pairs in group $A$. We have not yet located the NOR (which produces the secondary constriction) by silver staining in $R$. punctularia. In $R$. funerea the secondary constriction is on an acrocentric microchromosome adjacent to the centromere (Fig. 5a). The inversion of chromosome 9A of $R$. pulcherrima, $R$. rubida, and $R$. areolata could account for the acrocentric NOR-bearing chromosome of $R$. funerea. The NORs of $R$. areolata (Fig. 6a), R. p. incisa, and $R$. p. manni (Fig. 6b) were located, by silver staining, on the long arm of chromosome 9A. Virtually the entire long arm stains positive with silver in these species and this differs from species such as Ocadia sinensis (Fig. 1d) where only the terminal portion of the long arm stains. C-bands of $R$. areolata reveal the long arm of 9A to be heterochromatic (Fig. 6c). The G-banded macrochromosomes of $R$. areolata, $R$. pulcherrima incisa (Fig. 7a), and R. p. manni appear identical to each other and to those of $R$. punctularia (excepting there is one less group A pair in this species), Mauremys, and Sacalia (Bickham \& Baker, 1976a).

Rhinoclemmys punctularia is of special note because of its divergent karyotype. The nominal form $R$. p. punctularia differs from all other Rhinoclemmys examined, including $R . p$. melanosterna (Killebrew, 1977), in having two extra pairs of heterochromatic microchromosomes. Studies now show that $R$. p. punctularia is $2 \mathrm{n}=56$ in disjunct parts of its range, i.e. Trinidad (Bickham \& Baker, 1976a, b), Venezuela (present account), and Brazil (Barros et al., 1975).

\section{Heosemys complex}

Data are included for representatives of all of the genera in this group (Table 2). Pyxidea mouhotii (Fig. 7b), Heosemys spinosa, H. grandis (Fig. 7c), Cuora amboinensis (Fig. 8a), C. trifasciata (Fig. 8c), and Cyclemys dentata (Haiduk \& Bickham, 1982) all have the typical batagurine karyotype of $2 n=52$ (9:5:12). The NOR in Cuora and Pyxidea is located on the smallest group A chromosome pair, the same chromosome pair that is largely heterochromatic in Cyclemys (Haiduk \& Bick- ham, 1982). G-bands of Cuora amboinensis (Fig. 8b) show identical banding patterns of the macrochromosomes as the presumed primitive $2 \mathrm{n}=52$ karyotype, such as in Ocadia sinensis (Fig. 1b).

\section{Orlitia complex}

The diploid number is 50 and the arrangement 8:5:12 in both Orlitia and Siebenrockiella (Fig. 9a; Carr \& Bickham, 1981). A sex chromosome heteromorphism involving the second group B chromosome pair was found in Siebenrockiella (Carr \& Bickham, 1981). Males of Siebenrockiella are heteromorphic for centromere position on this chromosome and the females are homomorphic (an $\mathrm{XX} / \mathrm{XY}$ system). Differences between the $\mathrm{X}$ and the $Y$ and a discussion of their evolution is presented in Carr and Bickham (1981). The subtelocentric $\mathrm{X}$ chromosome of Siebenrockiella appears completely homologous in G-band pattern to the homomorphic second group B pair of Orlitia (Fig. 9a) and other emydids (Fig. 19 in Bickham \& Baker, 1976a). A possible difference in G-band pattern mentioned by Bickham and Baker (1976a) is probably due to comparison of chromosomes of different degrees of contraction. The NOR in Siebenrockiella is located telomerically on one of the larger pairs of microchromosomes (Fig. 10a), which is also largely heterochromatic (Fig. 2 in Carr \& Bickham, 1981). The NOR of Orlitia appears telomerically on a large microchromosome pair, as in Siebenrockiella (Fig. 10b). Orlitia differs from Siebenrockiella in having the centromere of the second group A macrochromosome pair within a dark G-band region (as it is in all other emydids), rather than within a light G-band region as in Siebenrockiella. The karyotype of Orlitia differs from that of Malayemys (Fig. 10c) and emydines (Fig. 10d) in the position of the NOR on the large microchromosome (i.e. telomeric rather than interstitial).

\section{Discussion}

\section{Karyotypic variation}

Some karyotypic data are available in the literature for 13 of the 23 batagurine genera, mostly con- 
cerning gross morphology (Bickham \& Carr, 1983). The present study has examined 24 species and subspecies in 16 genera, bringing the total number of genera for which karyotypic data are available to 18. Discrepancies between literature reports of diploid numbers and results obtained during this study are not usually considered to represent intraspecific karyotypic variation. It seems most likely that the discrepancies result from different levels of resolution achieved by the investigators, as all of the differences involve the number of microchromosomes.

The genera for which there are currently no karyotypic data available are Annamemys, Batagur, and those of the Hardella complex. Bickham (1975) and Bickham and Baker (1976a) considered the $2 n=52$ (9:5:12) karyotype exemplified by Mauremys and Sacalia to be primitive for the Batagurinae and the entire family. Essentially the same conclusion is implied or explicit in Killebrew (1977) and Dowler and Bickham (1982). In addition, the same karyotype is shared with some testudinids, a relationship interpreted as evidence for the hypothesized origin of tortoises from a 'proto-emydid' stock (Loveridge \& Williams, 1957; Bickham \& Baker, 1976a; Killebrew \& McKown, 1978; Dowler \& Bickham, 1982). Eleven other genera of batagurines have this same karyotype (Table 2; Bickham \& Carr, 1983). The genera Geoemyda and Kachuga should also be considered among this group possessing the primitive karyotype (Nakamura, 1949; Singh, 1972; Stock, 1972; Killebrew, 1977; DeSmet, 1978). All genera for which banding data are currently available show essentially identical G-band patterns with the NOR located on the largely heterochromatic ninth group A macrochromosome pair.

Three genera of Asian batagurines have $2 n=50$ karyotypes with eight group A and five group B pairs. Gross morphology of the chromosomes in Malayemys, Orlitia, and Siebenrockiella appears identical to that of the $2 n=50$ emydines, excepting the sex chromosomes of Siebenrockiella. The presence or absence of a sex chromosome system in Orlitia is unproved because we examined only a single juvenile (female?) specimen. The G-band patterns of Malayemys and Orlitia are the same as the emydines. Besides differences associated with the sex chromosome pair in Siebenrockiella, the second group A pair in Siebenrockiella has the centromere located in a G-band negative region whereas in oth- er emydids it is located in a G-positive region. The NOR of Orlitia and Siebenrockiella is located telomerically on a large heterochromatic microchromosome. In Malayemys (and emydines) the NOR is located interstitially. We have been unable to detect any karyotypic differences between the batagurine Malayemys and the emydines.

Five species of the Neotropical genus Rhinoclemmys have now been examined karyotypically. All but $R$. p. punctularia and $R$. funerea have been shown to be nearly identical to the presumed primitive $2 n=52$ (9:5:12) karyotype. The macrochromosomes of Rhinoclemmys species appear indistinguishable from those of other emydids except that the NOR appears to be in a slightly different position compared to the Asian $2 \mathrm{n}=52$ genera. $R$. funerea and $R$. p. punctularia have diverged from the modal Rhinoclemmys karyotype in having one less group A macrochromosome pair (8 rather than 9). Also, R. p. punctularia has two extra pairs of heterochromatic microchromosomes.

Rhinoclemmys is the only genus of cryptodiran turtles in which varaition in diploid number has been demonstrated (Bickham \& Baker, 1979). It is of interest that Killebrew (1977) reported $2 n=52$ in $R$. p. melanosterna. Since Boulenger (1889), the form melanosterna has been considered a subspecies $R$. punctularia. Ernst's (1978) recent revision of the genus also considered it as such. Pritchard $(1979 \mathrm{~b})$ regarded melanosterna to be a full species. $R$. p. melanosterna is found in eastern Panama, northern and western Colombia, and northwestern Ecuador. It is apparently geographically isolated from the neighboring $R$. p. diademata of northeastern Colombia and northwestern Venezuela by the Sierra de Perija. The nominal subspecies, $R . p$. punctularia, occurs in northeastern Venezuela, on Trinidad, and throughout the Guianan region into Amazonian Brazil. The forms punctularia and diademata are separated by the Sierra de Merida and central llanos of Venezuela (Pritchard, 1979b; Ernst, 1981). The great disjunction of range between the forms punctularia and melanosterna, taken together with the cytogenetic distinction between the two, leads us to agree with Pritchard (1979b) in considering melanosterna a distinct species. This view hinges, of course, on the accuracy of Killebrew's (1977) report of $2 n=52$ for $R$. p. melanosterna. Examination of the form diademata would be of interest because of its geo- 
graphic position relative to melanosterna and punctularia.

\section{Phylogenetic implications}

Most batagurine genera have retained the primitive $2 n=52$ (9:5:12) karyotype with the NOR located on the smallest group A macrochromosome, a karyotype shared with some testudinids (Dowler \& Bickham, 1982). In other emydids the NOR is located on a large microchromosome. A dichotomy occurs in which the $2 n=50$ karyotype is derived by loss of the 9th group A chromosome pair which formerly contained the NOR. It cannot be ruled out for certain that the NOR is not located on the same chromosome in both (that is, the $2 n=52$ and $2 n=50$ karyotypes) with that chromosome undergoing rearrangement, but there is certainly one less chromosome pair in the latter. This is the primitive condition proposed for members of the Orlitia complex, a karyotype retained by Orlitia. Another $2 n=50$ lineage relocated the NOR interstitially on the long arm of a large microchromosome pair. This is characteristic of the batagurine genus Malayemys and the emydines. The common possession of a derived karyotypic condition in these two separate groups is suggestive of a relationship which may be spurious due to convergence or may be indicative of a close relationship between Malayemys and those batagurines which gave rise to emydines (assuming Malayemys is not actually an emydine and that emydines arose from some batagurine). Figure 11 schematically represents the phylogenetic relationships among emydid turtles suggested by the latter scenario.

Rhinoclemmys stands as the only New World genus of the Batagurinae, a relationship supported by the karyotypic data (Bickham \& Baker, 1976a, b; Killebrew, 1977). The karyotypic data provide no real evidence of its relationships within the batagurines, as the primitive Rhinoclemmys karyotype differs only slightly from that of the entire subfamily. The chromosomally divergent $R$. p. punctularia and $R$. funerea would seem to have attained their derived karyotypes from more typical Rhinoclemmys, with $R$. p. punctularia being the most highly derived.

McDowell (1964) partitioned the emydids into two subfamilies and proposed several groups of related genera. It appears that all genera in the Emydinae possess identical karyotypes (Bickham \& Carr, 1983). The batagurines were grouped into four complexes of related genera by McDowell (1964), and Bramble (1974) subsequently added a

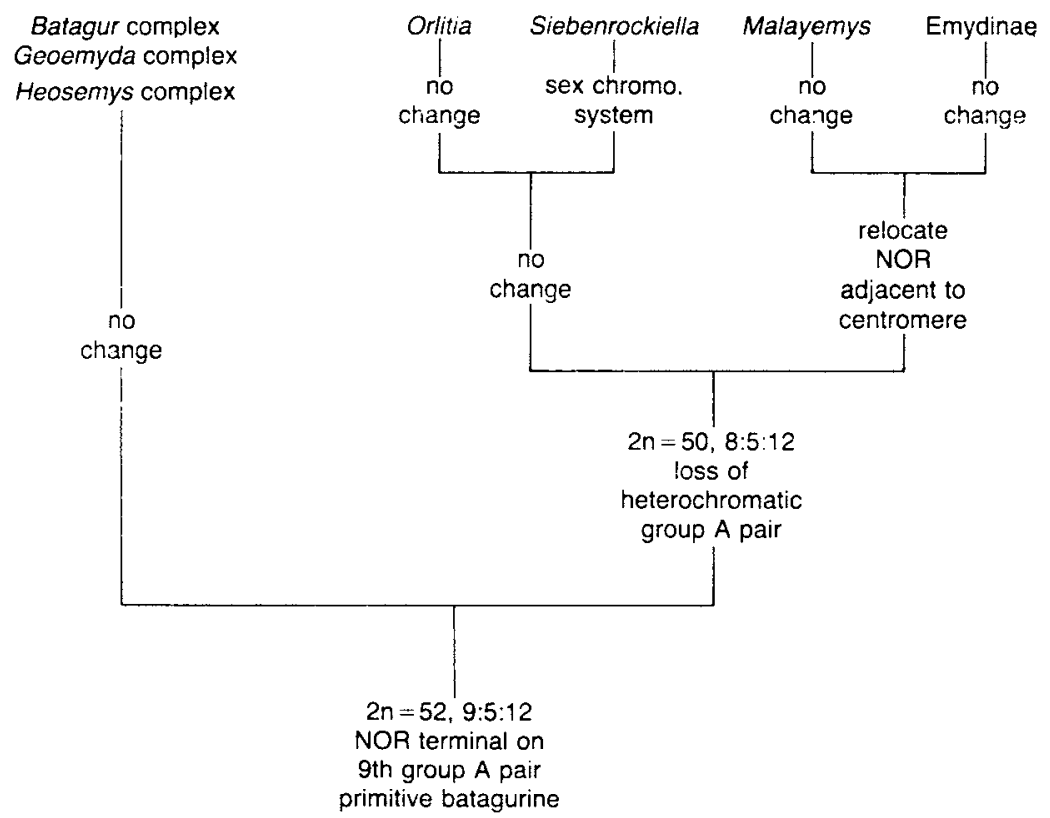

Fig. 11. Schematic representation of the phylogenetic relationships suggested by cladistic analysis of karyotypic data. 
fifth (Table 1). All but the Hardella complex have been karyotypically examined. Much of the proposed generic complex classification is untestable using karyology because so many batagurines have retained the primitive karyotype. The karyotypic data do support the close relationship between Orlitia and Siebenrockiella allied in the Orlitia complex. The inclusion of Malayemys in the Batagur complex is not supported by the karyotypic data. Its relationships would seem to lie somewhere between the Orlitia complex and the Emydinae (as depicted in Fig. 11). We consider the genus Malayemys as constituting its own, distinct generic assemblage, equivalent in rank to the other five previously proposed (Table 3 ).

Table 3. Suggested classification of generic groups in the Batagurinae.

\begin{tabular}{|c|c|}
\hline Hardella complex & (no karyotypic data) \\
\hline Batagur complex & $\begin{array}{l}2 n=52,9: 5: 12, \text { NOR on } 9 \text { th group } \\
\text { A pair }\end{array}$ \\
\hline Geoemyda complex & $\begin{array}{l}2 n=52,9: 5: 12, \text { NOR on } 9 \text { th group } \\
\text { A pair }\end{array}$ \\
\hline Heosemys complex & $\begin{array}{l}2 \mathrm{n}=52,9: 5: 12, \text { NOR on } 9 \text { th group } \\
\text { A pair }\end{array}$ \\
\hline Orlitia complex & $\begin{array}{l}2 \mathrm{n}=50,8: 5: 12, \text { NOR terminal on } \\
\text { microchromosome }\end{array}$ \\
\hline Malayemys complex & $\begin{array}{l}2 \mathrm{n}=50,8: 5: 12, \text { NOR proximal to } \\
\text { centromere on microchromosome }\end{array}$ \\
\hline
\end{tabular}

A recent study of biochemical relationships in the Batagurinae sheds some light on intergeneric relationships (Sites et al., 1984). As with karyotypes, the genera Siebenrockiella and Orlitia are shown to be closely related electrophoretically. Malayemys, however, appears most closely related to Ocadia, indicating the karyotypic divergence of Malayemys may be of relatively recent occurrence.

The generic groupings of McDowell (1964) and Bramble (1974) are not strongly supported by the karyological and electrophoretic data sets (with the exception of the Orlitia complex). However, it should be emphasized that karyology is too conservative (and electrophoresis too variable) to be very useful at this level of divergence in these turtles. Further study of batagurine systematics should employ biochemical or morphological features that have evolved at a rate intermediate between karyology and protein electrophoresis.

\section{Acknowledgements}

We thank Miguel Alvarez del Toro, Van Wallach, Douglas C. Robinson, Carl S. Lieb, John M. Legler, and Edward O. Moll for their help in obtaining specimens. James R. Dixon, Ira F. Greenbaum, Christopher P. Kofron, Robert H. Dean, Mark D. Engstrom, Jack W. Sites, Jr., and Mike W. Haiduk aided in the field work. Supported by NSF grants DEB-7713467 and DEB-7921519. This manuscript is part of a thesis submitted by the senior author in partial fulfillment of the requirements for the M.S. degree from Texas A\&M University. The authors wish to thank the other members of JLC's advisory committee for their help and guidance: Ira F. Greenbaum, David W. Owens, and James R. Dixon. Final manuscript preparation was aided by financial support to JLC from the Department of Biology, University of Utah.

\section{References}

Albrecht, P. W., 1976. The cranial arteries of turtles and their evolutionary significance. J. Morphol. 149: 159-182.

Barros, R. B., Sampaio, M. M., Assis, M. R., Ayres, M. \& Cunha, O., 1975. A karyological study of Geoemyda punctularia punctularia (Daudin, 1802) from the Amazon region of Brazil (Chelonia, Emydidae). Acta Amazon. 5: 95-96.

Bickham, J. W., 1975. A cytosystematic study of turtles in the genera Clemmys, Mauremys, and Sacalia. Herpetologica 31: 198-204.

Bickham, J. W. \& Baker, R. J., 1976a. Chromosome homology and evolution of emydid turtles. Chromosoma 54: 201-219.

Bickham, J. W. \& Baker, R. J., 1976b. Karyotypes of some neotropical turtles. Copeia 1976: $703-708$.

Bickham, J. W. \& Baker, R. J., 1979. Canalization model of chromosomal evolution. Bull. Carnegie Mus. Nat. Hist. 13: $70-84$.

Bickham, J. W., Bjorndal, K. A., Haiduk, M. W. \& Rainey, W. E., 1980. The karyotype and chromosomal banding patterns of the green turtle (Chelonia mydas). Copeia 1980: $540-543$.

Bickham, J. W. \& Carr, J. L., 1983. Taxonomy and phylogeny of the higher categories of cryptodiran turtles based on a cladistic analysis of chromosomal data. Copeia 1983: 918-932.

Boulenger, G. A., 1889. Catalogue of the Chelonians, Rhynchocephalians, and Crocodiles in the British Museum (Natural History). London: Trustees of the British Museum.

Bramble, D. M., 1974. Emydid shell kinesis: biomechanics and evolution. Copeia 1974: 707-727.

Carr, J. L. \& Bickham, J. W., 1981. Sex chromosomes of the Asian black pond turtle, Siebenrockiella crassicollis (Testudines: Emydidae). Cytogenet. Cell Genet. 31: 178-183.

DeSmet, W. H. O., 1978. The chromosomes of 11 species of Chelonia (Reptilia). Acta zool. path. antverpiensia No. 70: $15-34$. 
Dowler, R. C. \& Bickham, J. W., 1982. Chromosomal relationships of the tortoises (family Testudinidae). Genetica 58: $189-197$.

Ernst, C. H., 1978. A revision of the neotropical turtle genus Callopsis (Testudines: Emydidae: Batagurinae). Herpetologica 34: 113-134.

Ernst, C. H., 1981. Rhinoclemmys punctularia. Cat. Amer. Amph. Rept. 276: 1-2.

Goodpasture, C. \& Bloom, S. E., 1975. Visualization of nucleolar organizer regions in mammalian chromosomes using silver staining. Chromosoma 53: 37-50.

Haiduk, M. W. \& Bickham, J. W., 1982. Chromosomal homologies and evolution of testudinoid turtles with emphasis on the systematic placement of Platysternon. Copeia 1982: 60-66.

Killebrew, F., 1977. Mitotic chromosomes of turtles. IV. The Emydidae. Tex. J. Sci. 29: 245-253.

Killebrew, F. \& McKown, R. R., 1978. Mitotic chromosomes of Gopherus berlandieri and Kinixys belliana belliana (Testudines, Testudinidae). Southw. Nat. 23: 162-164.

Levan, A., Fredga, K. \& Sandbert, A. A., 1964. Nomenclature for centromeric position on chromosomes. Hereditas 50: $201-220$.

Loveridge, A. \& Williams, E. E., 1957. Revision of the African tortoises and turtles of the suborder Cryptodira. Bull. Mus. comp. Zool. 115: 163-557.

McDowell, S. B., 1961. On the major arterial canals in the earregion of testudinoid turtles and the classification of the Testudinoidea. Bull. Mus. Comp. Zool. 125: 23-39.

McDowell, S. B., 1964. Partition of the genus Clemmys and related problems in the taxonomy of the aquatic Testudinidae. Proc. Zool. Soc. London 143: 239-279.

Nakamura, K., 1949. A study in some chelonians with notes on chromosomal formula in the Chelonia. Kromosomo 5: $205-213$.

Parsons, T. S., 1968. Variation in the choanal structure of Recent turtles. Can. J. Zool. 46: 1235-1263.

Pritchard, P. C. H., 1979a. Taxonomy, evolution and zoogeography. In Turtles: Perspectives and research (M. Harless and $\mathbf{H}$. Morlock, eds). New York, Wiley, pp. 1-42.

Pritchard, P. C. H., 1979b. Encyclopedia of Turtles. Hong Kong: T. F. H. Publications.

Seabright, M., 1971. A rapid banding technique for human chromosomes. Lancet 1971-II: 971-972.

Singh, L.,1972. Karyological studies of three species of turtles from India. Indian Biologist 4: 64-69.

Sites, J. W., Jr., Bickham, J. W., Pytel, B. A., Greenbaum, I. F. \& Bates, B. A., 1984. Biochemical characters and the reconstruction of turtle phylogenies: relationships among batagurine genera. Syst. Zool. 33: 137-158.

Sites, J. W., Jr., Bickham, J. W., Haiduk, M. W. \& Iverson, J. B., 1979. G-banded karyotypes of six taxa of kinosternid turtles. Copeia 1979: 692-698.

Smith, H. M. \& James, L. F., 1958. The taxonomic significance of cloacal bursae in turtles. Trans. Kans. Acad. Sci. 61: 86-96.

Stock, A. D., 1972. Karyological relationships in turtles (Reptilia: Chelonia). Can. J. Genet. Cytol. 14: 859-868.

Sumner, A. T., 1972. A simple technique for demonstrating centromeric heterochromatin. Expl Cell Res. 75: 304-506.

Wermuth, H. \& Mertens, R., 1977. Liste der rezenten Amphibien und Reptilien. Testudines, Crocodylia, Rhynchocephalia. Das Tierreich 100: xxvii + $174 \mathrm{pp}$.

Received 1.2.1984 Accepted 26.5.1986. 